\title{
Preliminary Data on the Safety of Phytoene- and Phytofluene-Rich Products for Human Use including Topical Application
}

\author{
Fabien Havas $\mathbb{D}^{1}{ }^{1}$ Shlomo Krispin $\mathbb{D}^{1}{ }^{1}$ \\ Antonio J. Meléndez-Martínez $\mathbb{D}^{2}{ }^{2}$ and Liki von Oppen-Bezalel ${ }^{1}$ \\ ${ }^{1}$ IBR (Israeli Biotechnology Research) Ltd., 8122503 Yavne, Israel \\ ${ }^{2}$ Department of Nutrition \& Food Science, Universidad de Sevilla, 41012 Seville, Spain
}

Correspondence should be addressed to Fabien Havas; fhavas@ibrweb.com

Received 21 December 2017; Accepted 27 February 2018; Published 15 April 2018

Academic Editor: You-Cheng Hseu

Copyright (C) 2018 Fabien Havas et al. This is an open access article distributed under the Creative Commons Attribution License, which permits unrestricted use, distribution, and reproduction in any medium, provided the original work is properly cited.

The colorless carotenoids phytoene and phytofluene are comparatively understudied compounds found in common foods (e.g., tomatoes) and in human plasma, internal tissues, and skin. Being naturally present in common foods, their intake at dietary levels is not expected to present a safety concern. However, since the interest in these compounds in the context of many applications is expanding, it is important to conduct studies aimed at assessing their safety. We present here results of in vitro cytotoxicity and genotoxicity studies, revealing no significant cytotoxic or genotoxic potential and of short- and long-term human in vivo skin compatibility studies with phytoene- and phytofluene-rich tomato and Dunaliella salina alga extracts, showing a lack of irritancy or sensitization reactions. These results support the safe use of phytoene- and phytofluene-rich products in human topical applications.

\section{Introduction}

Dietary carotenoids are important compounds in the context of food science, nutrition, and health as they account for the color of many foods, some can be converted into compounds exhibiting vitamin A activity, and there is a large body of evidence indicating that they may exert health-promoting actions and contribute to reducing the risk of developing several diseases $[1,2]$. Their value as food colorants, components of functional foods, and related products such as dietary supplements and other over-the-counter healthcare products is therefore undeniable. There is also an expanding interest in these compounds in the context of nutricosmetics, a growing sector that includes products at the intersection between food, nutrition, health, and cosmetics. These can promote "beauty from within" and are usually referred to as "beauty foods," "beauty pills," or "oral cosmetics" $[3,4]$. Similarly, carotenoids have a long history of use in topical cosmetic formulations, aimed at delivering diverse beauty and personal care benefits like antiaging, anti-inflammation, antioxidation, and more [5-7].
Historically, the most studied carotenoids (and those most often used in carotenoid-linked health- and foodrelated claims) have been colored carotenoids such as lycopene, $\beta$-carotene, astaxanthin, or lutein. A relatively wide array of safety data is available regarding each of these compounds, as will be discussed later.

This is not the case for phytoene and phytofluene, which are considered the precursors of all colored carotenoids [8] and are rarities among carotenoids as they are colorless. This can explain in part the fact that phytoene and phytofluene have not been studied as intensively as other dietary carotenoids despite being present in widely consumed foods (tomatoes, citrus, carrots, among others) [9]. Besides, phytoene and phytofluene have been shown to be efficiently released from diverse food matrices using simulated in vitro digestions [10]; phytoene and phytofluene are present in human plasma, internal tissues, and skin [11-14]; and, more importantly, there are studies pointing to the fact that phytoene and phytofluene may be involved in diverse health-promoting actions. More specifically, phytoene and phytofluene could participate in antioxidant $[15,16]$ and 
anti-inflammatory actions [17, 18], decrease DNA damage in lymphocytes [19], and protect against skin and other types of cancer (leukemia, breast, endometrium, and prostate) [2024] and against light-induced erythema in the skin [25]. Interestingly, these colorless carotenoids could also participate in biological actions leading to cosmetic benefits. Thus, it has been recently reported that a 12 -week intervention with a freeze-dried natural tomato powder food supplement (Israeli Biotechnology Research Ltd. (IBR), Yavne, Israel) led to improvements in a series of skin quality parameters (skin radiance, suppleness, evenness, smoothness, moisturization, elasticity, visible skin health, visible skin youthfulness, and overall skin beauty) that were both clinically assessed and self-perceived by the volunteers [25]. The growing importance of the scarcely studied carotenoids phytoene and phytofluene across several research fields has been the subject of a dedicated comprehensive review [26].

Being naturally present in a variety of common and exotic dietary sources [26] their intake at dietary levels is not expected to pose important safety concerns. However, since their interest in the context of the diet, functional foods, and nutricosmetics is expected to expand considerably in the near future; and, considering the relative scarcity of data on this matter, it is important to conduct studies aimed at assessing their safety.

Following the above, we thus present herein results of several in vitro and topical in vivo human toxicological studies with additional phytoene- and phytofluene-rich liquid extracts from tomato and algal sources.

\section{Materials and Methods}

\subsection{In Vitro Toxicology: Cytotoxicity by Neutral Red Release (NRR) Protocol}

2.1.1. Phytoene- and Phytofluene-Rich Products Tested. Tested substances (Israeli Biotechnology Research Ltd. (IBR), Yavne, Israel) consisted of phytoene- and phytofluene-rich botanical extracts in oil carriers: (1) a tomato extract in squalene oil, containing ca. $0.75 \mathrm{mg} / \mathrm{mL}$ phytoene and phytofluene, and (2) an extract of Dunaliella salina alga in hydrogenated polydecene oil, containing ca. $1 \mathrm{mg} / \mathrm{mL}$ phytoene and phytofluene (both by UV spectrophotometry). Paraffin oil (aka mineral oil, Fluka) was used as negative control, as well as to dilute tested substances. An SDS solution (0.01, 0.05, and 0.20\%) served as positive control.

2.1.2. Experimental Conditions. The methodology was adapted from that described elsewhere [27]. The tested substances above were diluted and applied to a monolayer of rabbit cornea fibroblasts (SIRC \#2-552, CCL60; ATCC, Virginia USA) marked with a vital dye (Neutral Red). The cells were cultured in complete DMEM medium supplemented with decomplemented fetal calf serum and a penicillin/streptomycin solution, at $37^{\circ} \mathrm{C}$ under $5 \% \mathrm{CO}_{2}$. Cells were seeded and incubated for $24 \mathrm{~h}$, the culture medium was removed, and Neutral Red coloring solution was added. After $3 \mathrm{~h}$ further incubation, the coloring solution was removed and replaced by complete culture medium. The cells were
TABLE 1: Classification of cytotoxicity results in the NRR method.

\begin{tabular}{lcc}
\hline IC50 (\%) & $\begin{array}{c}\text { \% cell death at the } 50 \% \\
\text { dilution }\end{array}$ & Classification \\
\hline$>50$ & $<20$ & Negligible cytotoxicity \\
& $>20$ & Low cytotoxicity \\
$>25$ and $<50$ & & Moderate cytotoxicity \\
$<25$ & & High cytotoxicity \\
\hline
\end{tabular}

then maintained at room temperature for $30 \mathrm{~min}$, following which the wells were washed with PBS and treated with the diluted test products. Following 60 seconds' contact, the wells were washed with PBS. Acetic acid (in ethanol) was added, and after $15 \mathrm{~min}$ agitation the revealed solutions were transferred to 96-well plates (in duplicate) and optical density was read (Multiskan RC ascent 2.6 reader). The percentage of cell death was calculated as follows: $\%$ cell death $=100 \times(\mathrm{OD}$ of treated wells/OD of control wells). The tested substances were tested in dilutions at 5, 15, 25,35, and 50\%. The IC50 of each test item was then calculated by linear regression.

The results are then classified as described in Table 1.

\subsection{In Vitro Toxicology: Genotoxic Potential}

2.2.1. Phytoene- and Phytofluene-Rich Products Tested. The tested substance consisted of a hydrophobic phytoene- and phytofluene-rich Dunaliella salina extract (Israeli Biotechnology Research Ltd. (IBR), Yavne, Israel) in hexane, which was evaporated and then taken up in a like volume of ethanol and diluted $1 / 10$ to $1 / 10000$ with ultrapure water.

2.2.2. Experimental Conditions. The test method is part of a cell-free in vitro reconstitution of the repair process of DNA damage generated by Reactive Oxygen Species (ROS) [28], where highly purified plasmid DNA adsorbed onto sensitized wells were exposed for $30 \mathrm{~min}$ to the potential genotoxic agent and then repaired by exposure over $3 \mathrm{~h}$ to repair enzymes and dUTP-biotin, resulting in the incorporation of biotin moieties. These were then tagged by 15 -minute exposure to streptavidin and a chemiluminescent peroxidase substrate (5 $\mathrm{min}$ ), and the luminescence was quantified with a luminometer (SFRI Lumax 2).

The genotoxicity of the sample was evaluated according to the quantity of repairs thus detected (directly related to the amount of damage caused), as expressed by the ratio of luminescence obtained with the test sample to that of the solvent control. A repair ratio greater than 2 would indicate significant genotoxicity, while a ratio of less than 2 would indicate no significant genotoxicity. Methyl methanesulfonate (MMS) was used as a positive control.

\subsection{Topical Toxicology In Vivo (Human): $48 \mathrm{~h}$ Patch Testing}

2.3.1. Phytoene- and Phytofluene-Rich Products Tested. The tested substances consisted of a phytoene- and phytofluenerich tomato extract in hydrogenated polydecene or squalane oil carriers (Israeli Biotechnology Research Ltd. (IBR), Yavne, Israel), each containing ca. $0.75 \mathrm{mg} / \mathrm{mL}$ phytoene and 
phytofluene (by UV spectrophotometry), and a phytoeneand phytofluene-rich Dunaliella salina extract in hydrogenated polydecene oil, containing ca. $1.0 \mathrm{mg} / \mathrm{mL}$ phytoene and phytofluene (by UV spectrophotometry).

2.3.2. Experimental Conditions. The test method aims at evaluating the skin compatibility of the tested products, after a single skin application under controlled maximizing experimental conditions [29]. Each study included 10-11 subjects (subjects were healthy; male and female; $18-70$ years old; all skin types; Fitzpatrick phototypes I-V). Single patch applications of the test material (applied neat, without further dilution) were made on the subjects' back, under occlusive patches (Finn Chamber, Epitest Ltd.; Trumed ${ }^{\circledR}$; or IQ Ultra), for $48 \mathrm{~h}$. Distilled water was applied under a control patch.

2.3.3. Examinations and Observations. Skin compatibility of the tested substances was evaluated visually $15-30$ minutes after patch removal, based on skin examination of the treated and control areas and reporting of any sensations of discomfort by the test subjects. Observed erythema was graded on a 5-point scale from "no visible erythema" to "caustic effecterosive and/or necrotic aspect." Skin irritation was graded according to the International Contact Dermatitis Research Group scale (from "no reaction" to "extreme positive reaction"). The appearance of other signs of cutaneous reaction was also recorded, including infiltration/edema, papules, vesicles, bulla, petechiae, fissures, desquamation, dryness, hyper- or hypopigmentation, follicular reactions, exudation and/or surface encrustation, scabs, itching, heating, burning, and any extension of reactions beyond the area of the patch. Finally, observations were collected from study participants, and any other adverse events were recorded. An individual daily irritation score (IDIS) was calculated as follows: IDIS = sum of the grades obtained for visible clinical signs observed on the application area. Additionally a mean daily irritation score (MDIS) is calculated as follows: MDIS = $\sum$ (IDIS)/number of valid cases.

\subsection{Topical Toxicology In Vivo (Human): Repeat Insult Patch Testing (HRIPT)}

2.4.1. Phytoene- and Phytofluene-Rich Products Tested. The tested substances consisted of a phytoene- and phytofluenerich Dunaliella salina extract in hydrogenated polydecene oil, containing ca. $0.02 \mathrm{mg} / \mathrm{mL}$ phytoene and phytofluene (by UV spectrophotometry), and of a phytoene- and phytofluene-rich tomato fruit extract in squalane, containing ca. $0.75 \mathrm{mg} / \mathrm{mL}$ phytoene and phytofluene (by UV spectrophotometry) (Israeli Biotechnology Research Ltd. (IBR), Yavne, Israel).

2.4.2. Experimental Conditions. The studies were performed on 50 subjects each (subjects were healthy; male and female; 18-70 years old; all skin types; Fitzpatrick phototypes I-V). The test method used was the widely recognized protocol described by Marzulli and Maibach [30]. During the first phase (induction phase), nine patch applications of $20 \mu \mathrm{L}$ of the test material (applied neat, without further dilution)
TABLE 2: Genotoxicity results.

\begin{tabular}{lcc}
\hline Test substance & Dilution/concentration & Repair ratio \\
\hline \multirow{2}{*}{ Phytoene- and } & $1 / 10$ & 0.92 \\
phytofluene-rich Dunaliella & $1 / 100$ & 1.11 \\
extract & $1 / 1000$ & 1.18 \\
& $1 / 10000$ & 1.05 \\
\hline \multirow{2}{*}{ MMS } & $10 \mathrm{mM}$ & 6.26 \\
& $2 \mathrm{mM}$ & 2.44 \\
\hline
\end{tabular}

were made under occlusive Finn Chamber patches (Epitest Ltd.), on the same skin site on the subjects' back, over a 3 -week period. Each application lasted for 48 to $72 \mathrm{~h}$. Skin reactions were scored 15-30 minutes after removal of each patch application, following which a new patch application is performed. The induction phase was followed by a $2-4$ week rest phase, after which a single $48 \mathrm{~h}$ application (challenge phase) was carried out under the same conditions as above, both on the same skin site as used in the induction phase and on a corresponding fresh skin site on the opposite side of the subjects' back. Scoring of skin reactions was performed 30 minutes, and once more 48 hours, after removal of the challenge patch.

2.4.3. Examinations and Observations. The scoring of skin reactions was performed as follows: intensity of erythema and edema was assessed on an ordinal scale from "none" to "severe"; the appearance of main signs of cutaneous reaction was noted, such as erythema, edema, papules, vesicles, bulla, scabs, petechiae, fissures, desquamation, dryness, hyperor hypopigmentation or other discoloration, and follicular reactions. A grade was either assigned according to the International Contact Dermatitis Research Group (ICDRG) scale or calculated based on observed signs (mean daily irritation score $=\sum$ [individual daily irritation scores] $/$ number of subjects, where individual daily irritation scores were calculated based on grading of each observed sign of reaction).

\section{Results}

3.1. In Vitro Toxicology: Cytotoxicity by Neutral Red Release (NRR) Protocol. In the NRR protocol, both the tomato extract and the Dunaliella salina extract were classified as having negligible cytotoxicity, upon exhibiting an LD50 of over $50 \%$, and less than $20 \%$ cell death at the $20 \%$ dilution.

3.2. In Vitro Toxicology: Genotoxic Potential. The results of the test are summarized in Table 2.

According to the results shown in Table 2, the tested sample may be classified as having no genotoxic potential up to a $1 / 10$ dilution.

\subsection{Topical Toxicology In Vivo (Human): 48 h Patch Testing.} The results of the studies described in Section 2.3 are summarized in Table 3.

Based on the observations made during the $48 \mathrm{~h}$ Patch Testing, the phytoene- and phytofluene-rich extracts tested 
TABLE 3: $48 \mathrm{~h}$ patch test results.

\begin{tabular}{lccc}
\hline Test substance & Tomato extract in squalane & $\begin{array}{c}\text { Tomato extract in } \\
\text { hydrogenated polydecene }\end{array}$ & $\begin{array}{c}\text { Dunaliella extract in } \\
\text { hydrogenated polydecene }\end{array}$ \\
\hline Reactions noted & None & None & None \\
\# reactive subjects (\%) & $0(0 \%)$ & $0(0 \%)$ & $0(0 \%)$ \\
MDIS & 0 & 0 & 0 \\
Conclusion & Very good skin & Very good skin & Very good skin \\
compatibility/nonirritant & compatibility/nonirritant & compatibility/nonirritant \\
\hline
\end{tabular}

may be classified as nonirritant and having very good skin compatibility.

\subsection{Topical Toxicology In Vivo (Human): Repeat Insult Patch} Testing (HRIPT). During the induction phase, no clinically significant objective signs of skin reaction were noted in any subjects with either product tested.

With the Dunaliella extract, the average erythema grade was 1 (slight erythema only). During the challenge phase, once again no clinically significant objective signs of skin reaction were noted in any subjects (ICDRG grade $=0$, no reaction). Overall irritation grades were recorded as 0.00 for both the induction and the challenge phase. No significant clinical adverse event was noted during the study.

With the tomato extract, the mean daily irritation score was 0 at every testing point in the study.

Therefore, it may be concluded that the tested extracts did not induce any sensitization or allergic reactions and are very well tolerated on human skin.

\section{Discussion}

The different pieces of experimental evidence presented in this paper point to the fact that the use of colorless carotenoids phytoene and phytofluene in topical formulations does not pose important safety concerns. Apart from this, there are other pieces of evidence indicating that these compounds are part of the common diets of many ethnicities, that they are present in human fluids and tissues, and that they may even provide health and cosmetic benefits, as summarized in the introduction. In relation to the presumable safety of phytoene and phytofluene it is to be noted that there is ample evidence concerning the safety of the other major carotenoids found in humans and in amounts much higher than those commonly achievable through the diet.

4.1. Dietary Sources of Phytoene and Phytofluene. Almost without exception, phytoene and phytofluene levels in foods have not been included in food composition tables or databases [31-36] or in dedicated studies [9, 37, 38]. However, this situation is expected to change in the near future as evidence is accumulating that phytoene and phytofluene can provide health benefits $[26,39]$, which is expected to lead to heightened interest in these compounds.

However, phytoene and phytofluene can be found in common foods in Western diets like apricot, cantaloupe, banana, carrot, melon, oranges, peppers, watermelon, lemon, clementines, grapefruits, avocado, mandarin, nectarine, peach, and a wide variety of tomatoes and derivatives (reviewed in [26]) and in other more exotic and highly nondomesticated foods. Examples of the latter would be caja [40], buriti, mamey, marimari, physalis [41], or gac [42], among others. It is noteworthy that phytoene and phytofluene are also found in ancient Andean wild relatives of the domesticated tomato [43]. Thus, it can be inferred that phytoene and phytofluene are common in the diet of humans from different geographical regions and ethnicities and that it is sensible to think that they have been part of their diet for centuries if not millennia.

4.2. Phytoene and Phytofluene Intakes. The carotenoid intakes reported in different countries are summarized in Table 4.

Phytoene and phytofluene have not been taken into account in most dietary intake studies. Recently, these were estimated to be $2.0 \mathrm{mg}$ and $0.7 \mathrm{mg}$, respectively, in Luxembourg [6]. The fact that the intakes of phytoene were second only to $\alpha-+\beta$-carotene and that these intakes were higher than those of lycopene $(1.8 \mathrm{mg})$ is noteworthy. Higher intakes of phytoene relative to lycopene may also be expected in other countries. Phytoene and phytofluene typically accompany lycopene in the dietary sources of the latter (e.g., tomato and derivatives, watermelons, and red-fleshed citrus), although their levels are normally considerably lower [9, 44-47]. However, the distribution of the colorless carotenoids among dietary sources seems to be broader as these compounds are also found in widely consumed fruits and vegetables that do not contain detectable levels of lycopene, like most carrots, peaches, nectarines, red peppers, oranges, and other citrus varieties [26].

4.3. Safety of Dietary Carotenoids. Being naturally biosynthesized by all plants, it can be claimed that carotenoids have always been present in the diet of the human species. Thus, all green leaves and other plant photosynthetic tissues contain high amounts of lutein and the provitamin $\mathrm{A} \beta$-carotene [48], two carotenoids bioavailable in humans that are thought to provide health benefits $[2,49]$. Likewise, other plant foods (roots, fruits, and seeds) provide other health-promoting carotenoids like lycopene, $\beta$-cryptoxanthin, zeaxanthin, phytoene, and phytofluene [26, 39, 50-55]. Interestingly, the first natural food of newborns, their mothers' milk, contains carotenoids, including phytoene and phytofluene, with high levels of lutein, which is thought to be important for their 
TABLE 4: Reported carotenoid intakes (mg/day) in different countries. Adapted from Maiani et al. (2009) and Biehler et al. (2012).

\begin{tabular}{lcccccccc}
\hline Country & $\mathrm{TI}^{*}$ & $\mathrm{~L}+\mathrm{Z}$ & $\mathrm{BCR}$ & $\mathrm{LYC}$ & $\mathrm{ACA}$ & $\mathrm{BCA}$ & PT & PTF \\
\hline Germany & 9.37 & 4.87 & 0.28 & 0.75 & 0.28 & 3.09 & n.r. & n.r. \\
Denmark & 10.10 & 5.25 & 0.40 & 0.71 & 0.30 & 3.43 & n.r. & n.r. \\
Italy & 15.73 & 7.09 & 0.63 & 2.36 & 0.47 & 5.20 & n.r. & n.r. \\
Sweden & 7.52 & 3.61 & 0.38 & 0.83 & 0.23 & 2.41 & n.r. & n.r. \\
UK & 8.65 & 4.33 & 0.35 & 0.78 & 0.26 & 2.86 & n.r. & n.r. \\
Greece & 20.97 & 8.39 & 0.63 & 4.40 & 0.84 & 6.71 & n.r. & n.r. \\
France & 13.98 & 6.99 & 0.56 & 1.26 & 0.42 & 4.75 & n.r. & n.r. \\
Netherlands & 8.76 & 4.21 & 0.44 & 0.88 & 0.26 & 2.89 & n.r. & n.r. \\
Spain & 12.79 & 5.76 & 0.51 & 1.79 & 0.38 & 4.35 & n.r. & n.r. \\
Luxembourg & 15.30 & 1.80 & 1.40 & 1.80 & & $7.60^{* *}$ & 2.00 & 0.70 \\
\hline
\end{tabular}

L: lutein; Z: zeaxanthin; BCR: $\beta$-cryptoxanthin; LYC: lycopene; ACA: $\alpha$-carotene; BCA: $\beta$-carotene; PT: phytoene; PTF: phytofluene; n.r.: not reported; ${ }^{*}$ total Intake (TI): sum of the individual values of $\mathrm{L}+\mathrm{Z}, \mathrm{BCR}, \mathrm{LYC}, \mathrm{ACA}$, and BCA (and also of the levels of PT and PTF in the case of Luxembourg); ${ }^{* *}$ sum of the intakes of ACA + BCA.

development $[49,56]$. Phytoene and phytofluene have also been reported in plasma at concentrations within the range 0 $1 \mu \mathrm{M}[11,19,57-60]$ and in several human tissues (liver, lung, breast, cervix, prostate, colon, and skin) at levels in the range of ng/g [13]. Taking all these facts into consideration it can be presumed that carotenoids at dietary levels are safe and that these compounds could even provide diverse health benefits.

4.3.1. Safety Data of Other Major Dietary Carotenoids. There is ample evidence that $\beta$-carotene from diverse sources (synthetic, plants, algae, and fungi) is a safe compound. $\mathrm{LD}_{50}$ values up to over $20000 \mathrm{mg} / \mathrm{kg}$ and No-Observed-AdverseEffect Level (NOAEL) from 696 up to $4175 \mathrm{mg} / \mathrm{kg}$ body weight/day have been reported. The EFSA Panel on Food Additives and Nutrient Sources added to food stated that "the use of $\beta$-carotene [E 160a (ii)] as food color [is] not of safety concern, provided that the estimated combined intake from their use as a food additive and as food supplement, is not more than the amount likely to be ingested as a result of the regular consumption of the foods in which they occur naturally (5-10 mg/day)." [61].

Values of $\mathrm{LD}_{50}$ over $2000 \mathrm{mg} / \mathrm{kg}$ and NOAEL between 200 and $1000 \mathrm{mg} / \mathrm{kg}$ body weight/day have been reported for lutein. Moreover, the EFSA Panel on Food Additives and Nutrient Sources added to Food established an ADI of $1 \mathrm{mg} / \mathrm{kg}$ body weight/day [62]. Several lutein products have been categorized as GRAS by the FDA [63-68].

Values of $\mathrm{LD}_{50}$ over $3000 \mathrm{mg} / \mathrm{kg}$ body weight and of NOAEL ranging from 50 to $600 \mathrm{mg} / \mathrm{kg}$ body weight/day have been reported for lycopene. The Panel on Food Additives, Flavorings, Processing Aids, and Materials in Contact with Food derived an ADI of $0.5 \mathrm{mg} / \mathrm{kg}$ body weight/day for lycopene from all sources. The panel also stated that the ADI applies to lycopene from tomatoes, [69]. The EFSA Panel on Dietetic Products, Nutrition and Allergies also provided an opinion on the safety of a lycopene oleoresin from non-GM high-lycopene tomatoes. This product contained 5-15\% lycopene, phytoene $(0.5-0.75 \%)$, phytofluene $(0.4-0.65 \%)$, and $\beta$-carotene $(0.2-0.35 \%)$, as well as other lipophilic compounds, including tocopherols $(1.5-3 \%)$. The panel stated that the lycopene oleoresin was as safe as lycopene from other accepted sources [70]. Several lycopene or lycopene-rich products have been categorized as GRAS by the FDA, including synthetic lycopene [71], tomato lycopene [71], tomato pulp powder [72], concentrated tomato lycopene extract [73], and even lycopene produced by Escherichia coli expressing lycopene biosynthetic enzymes [74].

Values of $\mathrm{LD}_{50}$ over $8000 \mathrm{mg} / \mathrm{kg}$ [75] and NOAEL of $150 \mathrm{mg} / \mathrm{kg}$ body weight per day have been reported for synthetic zeaxanthin. The EFSA Panel on Dietetic Products, Nutrition and Allergies has concluded that daily intakes of $0.75 \mathrm{mg} / \mathrm{kg}$ body weight do not raise safety concerns [76]. Several zeaxanthin products have been categorized as GRAS by the FDA, including zeaxanthin from Capsicum annuum [77] and marigold (Tagetes erecta) [78].

\section{Conclusions}

Carotenoids are natural compounds widespread in foods that are naturally present in the diet and can be used as additives or ingredients of supplements. They are present in human plasma and tissues. There is ample toxicological evidence concerning their safety, and indeed there are carotenoids or carotenoid-containing products categorized as GRAS by the US FDA. On the other hand, EFSA has established ADIs of 0.5 and $1 \mathrm{mg} / \mathrm{kg}$ body weight/day for the common dietary carotenoids lycopene and lutein, respectively. This means that daily intakes of 30 and $60 \mathrm{mg}$ of such carotenoids by a person of $60 \mathrm{~kg}$ are not considered of safety concern. These intakes are considerable higher than the daily total dietary carotenoid intakes assessed in several countries (ranging from ca. 7.5 to $21 \mathrm{mg} /$ day, Table 2).

The colorless carotenoids phytoene and phytofluene are present in widely consumed foods (like tomatoes, citrus, or carrots among many others) as well as in human plasma, milk, internal tissues, and skin. Some studies suggest that phytoene and phytofluene may be involved in diverse healthpromoting actions. Thus, phytoene and phytofluene could act as antioxidants or anti-inflammatory compounds or protect against cancer and light-induced damage in the skin. Being naturally present in common and exotic foods, including ancient wild relatives of the domesticated tomato, 
their intake at dietary levels is not expected to be of safety concern. However, since their interest in the context of the diet, functional foods, and nutricosmetics is expanding, it is important to conduct studies aimed at assessing their safety.

Thus, we present herein the results of in vitro cytotoxicity studies (NRR protocol) on phytoene- and phytofluene-rich extracts from two sources (tomato and Dunaliella salina), showing that these extracts have negligible cytotoxicity in this model; by an in vitro genotoxicity study on a phytoeneand phytofluene-rich extract of Dunaliella salina, showing no genotoxic potential for this extract in the tested model; by in vivo (human) $48 \mathrm{~h}$ patch tests of three phytoeneand phytofluene-rich extracts from two sources (tomato and Dunaliella salina), showing that these extracts have very good skin compatibility; and by a longer-term Human Repeat Insult Patch Test of a phytoene- and phytofluene-rich Dunaliella salina extract, showing that the tested extract did not induce any skin sensitization and was very well tolerated on human skin.

The facts that both EFSA and FDA have provided positive opinions concerning the safety of tomato products and that these contain phytoene and phytofluene at lower amounts relative to lycopene but still high, considering the classification of Britton and Khachik [26, 79], adds support to the safety of phytoene and phytofluene as food ingredients. The above data speak strongly in favor of the safe use of phytoene- and phytofluene-rich products for a variety of human uses. In this light and that of other data on the safety of other dietary carotenoids, it would not be surprising that ADIs comparable to those established for lycopene or lutein could eventually be established for phytoene and phytofluene, although, of course, the pertinent toxicological studies will need to be performed.

\section{Conflicts of Interest}

Fabien Havas, Shlomo Krispin, and Liki von Oppen-Bezalel are employees of IBR (Israeli Biotechnology Research) Ltd. Antonio J. Meléndez-Martínez is a member of the advisory board of IBR (Israeli Biotechnology Research) Ltd.

\section{Authors' Contributions}

Shlomo Krispin, Liki von Oppen-Bezalel, and Fabien Havas contributed to producing the data presented herein as well as to its analysis and interpretation and to the drafting and reviewing of the manuscript. Antonio J. Meléndez-Martínez contributed to the analysis and interpretation of data as well as to the drafting and reviewing of the manuscript.

\section{Acknowledgments}

The research leading to these results was funded in part by the European Community's Seventh Framework Program (FP7/2007-2013) under Grant Agreement 613513 (Project DISCO).

\section{References}

[1] F. Delgado-Vargas, A. R. Jiménez, and O. Paredes-López, "Natural pigments: carotenoids, anthocyanins, and betalains-characteristics, biosynthesis, processing, and stability," Critical Reviews in Food Science and Nutrition, vol. 40, no. 3, pp. 173289, 2000.

[2] N. I. Krinsky and E. J. Johnson, "Carotenoid actions and their relation to health and disease," Molecular Aspects of Medicine, vol. 26, no. 6, pp. 459-516, 2005.

[3] T. P. Anunciato and P. A. da Rocha Filho, "Carotenoids and polyphenols in nutricosmetics, nutraceuticals, and cosmeceuticals," Journal of Cosmetic Dermatology, vol. 11, no. 1, pp. 51-54, 2012.

[4] S. Madhere and P. Simpson, "A market overview of nutricosmetics," Cosmetic Dermatology, vol. 23, no. 6, pp. 268-274, 2010.

[5] Y. Tanaka, N. Sasaki, and A. Ohmiya, "Biosynthesis of plant pigments: Anthocyanins, betalains and carotenoids," The Plant Journal, vol. 54, no. 4, pp. 733-749, 2008.

[6] L. von Oppen-Bezalel and A. Shaish, "Application of the Colorless Carotenoids, Phytoene, and Phytofluene in Cosmetics, Wellness, Nutrition, and Therapeutics," in The Alga Dunaliella: Biodiversity, Physiology, Genomics and Biotechnology, A. BenAmotz, J. Polle, and S. Rao, Eds., pp. 423-444, Science Publishers, Enfield, NH, USA, 2009.

[7] L. von Oppen-Bezalel, E. Lerner, D. Kern, B. Fuller, E. Soudant, and A. Shaish, "IBR-CLC ${ }^{\circledR}$, Colorless Carotenoids: Phytoene and Phytofluene from Unicellular Algae - Applications in Cosmetics, Wellness and Nutrition," Flavour and Fragrance Journal, vol. 34, pp. 48-53, 2006.

[8] P. D. Fraser and P. M. Bramley, "The biosynthesis and nutritional uses of carotenoids," Progress in Lipid Research, vol. 43, no. 3, pp. 228-265, 2004.

[9] E. Biehler, A. Alkerwi, L. Hoffmann et al., "Contribution of violaxanthin, neoxanthin, phytoene and phytofluene to total carotenoid intake: Assessment in Luxembourg," Journal of Food Composition and Analysis, vol. 25, no. 1, pp. 56-65, 2012.

[10] P. Mapelli-Brahm, J. Corte-Real, A. J. Meléndez-Martínez, and T. Bohn, "Bioaccessibility of phytoene and phytofluene is superior to other carotenoids from selected fruit and vegetable juices," Food Chemistry, vol. 229, pp. 304-311, 2017.

[11] I. Paetau, F. Khachik, E. D. Brown et al., "Chronic ingestion of lycopene-rich tomato juice or lycopene supplements significantly increases plasma concentrations of lycopene and related tomato carotenoids in humans," American Journal of Clinical Nutrition, vol. 68, no. 6, pp. 1187-1195, 1998.

[12] A. J. Melendez-Martinez, C. M. Stinco, C. Liu, and X.-D. Wang, "A simple HPLC method for the comprehensive analysis of cis/trans (Z/E) geometrical isomers of carotenoids for nutritional studies," Food Chemistry, vol. 138, no. 2-3, pp. 1341-1350, 2013.

[13] F. Khachik, L. Carvalho, P. S. Bernstein, G. J. Muir, D.-Y. Zhao, and N. B. Katz, "Chemistry, distribution, and metabolism of tomato carotenoids and their impact on human health," Experimental Biology and Medicine, vol. 227, no. 10, pp. 845-851, 2002.

[14] T. R. Hata, T. A. Scholz, I. V. Ermakov et al., "Non-invasive Raman spectroscopic detection of carotenoids in human skin," Journal of Investigative Dermatology, vol. 115, no. 3, pp. 441-448, 2000.

[15] A. Shaish, A. Harari, Y. Kamari, E. Soudant, D. Harats, and A. Ben-Amotz, "A carotenoid algal preparation containing 
phytoene and phytofluene inhibited LDL oxidation in vitro," Plant Foods for Human Nutrition, vol. 63, no. 2, pp. 83-86, 2008.

[16] A. Ben-Dor, M. Steiner, L. Gheber et al., "Carotenoids activate the antioxidant response element transcription system," Molecular Cancer Therapeutics, vol. 4, no. 1, pp. 177-186, 2005.

[17] B. Fuller, D. Smith, A. Howerton, and D. Kern, "Anti-inflammatory effects of CoQ10 and colorless carotenoids," Journal of Cosmetic Dermatology, vol. 5, no. 1, pp. 30-38, 2006.

[18] S. Y. Bu, “Transitional changes in energy intake, skeletal muscle content and nutritional behavior in college students during course-work based nutrition education," Clinical Nutrition Research, vol. 2, no. 2, pp. 125-134, 2013.

[19] M. Porrini, P. Riso, A. Brusamolino, C. Berti, S. Guarnieri, and F. Visioli, "Daily intake of a formulated tomato drink affects carotenoid plasma and lymphocyte concentrations and improves cellular antioxidant protection," British Journal of Nutrition, vol. 93, no. 1, pp. 93-99, 2005.

[20] M. M. Mathews-Roth, "Antitumor activity of $\beta$-carotene, canthaxanthin and phytoene," Oncology (Switzerland), vol. 39, no. 1, pp. 33-37, 1982.

[21] E. Nara, H. Hayashi, M. Kotake, K. Miyashita, and A. Nagao, "Acyclic Carotenoids and Their Oxidation Mixtures Inhibit the Growth of HL-60 Human Promyelocytic Leukemia Cells," Nutrition and Cancer, vol. 39, no. 2, pp. 273-283, 2001.

[22] K. Hirsch, A. Atzmon, M. Danilenko, J. Levy, and Y. Sharoni, "Lycopene and other carotenoids inhibit estrogenic activity of 17 $\beta$-estradiol and genistein in cancer cells," Breast Cancer Research and Treatment, vol. 104, no. 2, pp. 221-230, 2007.

[23] E. Kotake-Nara, M. Kushiro, H. Zhang, T. Sugawara, K. Miyashita, and A. Nagao, "Carotenoids affect proliferation of human prostate cancer cells," Journal of Nutrition, vol. 131, no. 12, pp. 3303-3306, 2001.

[24] J. K. Campbell, C. K. Stroud, M. T. Nakamura, M. A. Lila, and J. W. Erdman Jr., "Serum testosterone is reduced following shortterm phytofluene, lycopene, or tomato powder consumption in F344 rats," Journal of Nutrition, vol. 136, no. 11, pp. 2813-2819, 2006.

[25] L. v. Bezalel, D. Fishbein, F. Havas, O. Ben-Chitrit, and A. Khaiat, "The photoprotective effects of a food supplement tomato powder rich in phytoene and phytofluene, the colorless carotenoids, a preliminary study," Global Dermatology, vol. 2, no. $4,2015$.

[26] A. J. Meléndez-Martínez, P. Mapelli-Brahm, A. BenítezGonzález, and C. M. Stinco, "A comprehensive review on the colorless carotenoids phytoene and phytofluene," Archives of Biochemistry and Biophysics, vol. 572, pp. 188-200, 2015.

[27] S. J. Reader, V. Blackwell, R. O’Hara, R. H. Clothier, G. Griffin, and M. Balls, "Neutral red release from pre-loaded cells as an in vitro approach to testing for eye irritancy potential," Toxicology in Vitro, vol. 4, no. 4-5, pp. 264-266, 1990.

[28] B. Salles, C. Provot, P. Calsou, I. Hennebelle, I. Gosset, and G. J. Fournié, "A chemiluminescent microplate assay to detect DNA damage induced by genotoxic treatments," Analytical Biochemistry, vol. 232, no. 1, pp. 37-42, 1995.

[29] P. J. Frosch and A. M. Kligman, "The Duhring chamber: An improved technique for epicutaneous testing of irritant and allergic reactions," Contact Dermatitis, vol. 5, no. 2, pp. 73-81, 1979.

[30] F. N. Marzulli and H. I. Maibach, "The use of graded concentrations in studying skin sensitizers: Experimental contact sensitization in man," Food and Cosmetics Toxicology, vol. 12, no. 2, pp. 219-227, 1974.
[31] B. Beltrán, R. Estévez, C. Cuadrado, S. Jiménez, and B. Olmedilla Alonso, "Base de datos de carotenoides para valoración de la ingesta dietética de carotenos, xantofilas y de vitamina A: utilización en un estudio comparativo del estado nutricional en vitamina A de adultos jóvenes," Nutricion Hospitalaria, vol. 27, pp. 1334-1343, 2012.

[32] J. M. Holden, A. L. Eldridge, G. R. Beecher et al., "Carotenoid content of U.S. foods: an update of the database," Journal of Food Composition and Analysis, vol. 12, no. 3, pp. 169-196, 1999.

[33] M. Murkovic, K. Gams, S. Draxl, and W. Pfannhauser, "Development of an Austrian carotenoid database," Journal of Food Composition and Analysis, vol. 13, no. 4, pp. 435-440, 2000.

[34] M. E. O’Neill, Y. Carroll, B. Corridan et al., "A European carotenoid database to assess carotenoid intakes and its use in a five-country comparative study," British Journal of Nutrition, vol. 85, no. 4, pp. 499-507, 2001.

[35] D. B. Rodriguez-Amaya, M. Kimura, H. T. Godoy, and J. AmayaFarfan, "Updated Brazilian database on food carotenoids: Factors affecting carotenoid composition," Journal of Food Composition and Analysis, vol. 21, no. 6, pp. 445-463, 2008.

[36] C. Reif, E. Arrigoni, H. Schärer, L. Nyström, and R. F. Hurrell, "Carotenoid database of commonly eaten Swiss vegetables and their estimated contribution to carotenoid intake," Journal of Food Composition and Analysis, vol. 29, no. 1, pp. 64-72, 2013.

[37] M. G. Dias, M. F. G. F. C. Camões, and L. Oliveira, "Carotenoids in traditional Portuguese fruits and vegetables," Food Chemistry, vol. 113, no. 3, pp. 808-815, 2009.

[38] R. Monge-Rojas and H. Campos, "Tocopherol and carotenoid content of foods commonly consumed in Costa Rica," Journal of Food Composition and Analysis, vol. 24, no. 2, pp. 202-216, 2011.

[39] N. J. Engelmann, S. K. Clinton, and J. W. Erdman, "Nutritional aspects of phytoene and phytofluene, carotenoid precursors to lycopene," Advances in Nutrition, vol. 2, no. 1, pp. 51-61, 2011.

[40] P. S. Hamano and A. Z. Mercadante, "Composition of carotenoids from commercial products of caja (Spondias lutea)," Journal of Food Composition and Analysis, vol. 14, no. 4, pp. 335343, 2001.

[41] V. V. De Rosso and A. Z. Mercadante, "Identification and quantification of carotenoids, by HPLC-PDA-MS/MS, from Amazonian fruits," Journal of Agricultural and Food Chemistry, vol. 55, no. 13, pp. 5062-5072, 2007.

[42] B. K. Ishida, C. Turner, M. H. Chapman, and T. A. McKeon, "Fatty Acid and Carotenoid Composition of Gac (Momordica cochinchinensis Spreng) Fruit," Journal of Agricultural and Food Chemistry, vol. 52, no. 2, pp. 274-279, 2004.

[43] A. J. Meléndez-Martínez, P. D. Fraser, and P. M. Bramley, "Accumulation of health promoting phytochemicals in wild relatives of tomato and their contribution to in vitro antioxidant activity," Phytochemistry, vol. 71, no. 10, pp. 1104-1114, 2010.

[44] C.-J. Xu, P. D. Fraser, W.-J. Wang, and P. M. Bramley, "Differences in the carotenoid content of ordinary citrus and lycopene-accumulating mutants," Journal of Agricultural and Food Chemistry, vol. 54, no. 15, pp. 5474-5481, 2006.

[45] B. Alquezar, M. J. Rodrigo, and L. Zacarías, "Regulation of carotenoid biosynthesis during fruit maturation in the redfleshed orange mutant Cara Cara," Phytochemistry, vol. 69, no. 10, pp. 1997-2007, 2008.

[46] L. H. Tonucci, J. M. Holden, G. R. Beecher, F. Khachik, C. S. Davis, and G. Mulokozi, "Carotenoid content of thermally processed tomato-based food products," Journal of Agricultural and Food Chemistry, vol. 43, no. 3, pp. 579-586, 1995. 
[47] C. M. Stinco, F. J. Heredia, I. M. Vicario, and A. J. MeléndezMartínez, "In vitro antioxidant capacity of tomato products: Relationships with their lycopene, phytoene, phytofluene and alpha-tocopherol contents, evaluation of interactions and correlation with reflectance measurements," LWT-Food Science and Technology, vol. 65, pp. 718-724, 2016.

[48] G. Britton, "Worked examples of isolation and analysis. Example 1: Higher plants," in Carotenoids. Vol. $1 A$ Isolation and Analysis, G. Britton, S. Liaaen-Jensen, and H. Pfander, Eds., pp. 201-214, Birkhäuser, Basel, Switzerland, 1995.

[49] E. J. Johnson, "Role of lutein and zeaxanthin in visual and cognitive function throughout the lifespan," Nutrition Reviews, vol. 72, no. 9, pp. 605-612, 2014.

[50] M. Yamaguchi, " $\beta$-cryptoxanthin and bone metabolism: The preventive role in osteoporosis," Journal of Health Science, vol. 54, no. 4, pp. 356-369, 2008.

[51] F. Lian, K.-Q. Hu, R. M. Russell, and X.-D. Wang, " $\beta$-cryptoxanthin suppresses the growth of immortalized human bronchial epithelial cells and non-small-cell lung cancer cells and up-regulates retinoic acid receptor $\beta$ expression," International Journal of Cancer, vol. 119, no. 9, pp. 2084-2089, 2006.

[52] E. J. Johnson, "A possible role for lutein and zeaxanthin in cognitive function in the elderly," American Journal of Clinical Nutrition, vol. 96, no. 5, pp. 1161S-1165S, 2012.

[53] M. G. Sajilata, R. S. Singhal, and M. Y. Kamat, “The carotenoid pigment zeaxanthin - A review," Comprehensive Reviews in Food Science and Food Safety, vol. 7, no. 1, pp. 29-49, 2008.

[54] E. C. Miller, E. Giovannucci, J. W. Erdman Jr., R. Bahnson, S. J. Schwartz, and S. K. Clinton, "Tomato products, lycopene, and prostate cancer risk," Urologic Clinics of North America, vol. 29, no. 1, pp. 83-93, 2002.

[55] N. I. Krinsky, "Overview of Lycopene, Carotenoids, and Disease Prevention," Experimental Biology and Medicine, vol. 218, no. 2, pp. 95-97, 1998.

[56] F. Khachik, C. J. Spangler, J. C. Smith, and L. M. Canfield, "Identification, quantification, and relative concentrations of carotenoids and their metabolites in human milk and serum," Analytical Chemistry, vol. 69, no. 10, pp. 1873-1881, 1997.

[57] H. Müller, A. Bub, B. Watzl, and G. Rechkemmer, "Plasma concentrations of carotenoids in healthy volunteers after intervention with carotenoid-rich foods," European Journal of Nutrition, vol. 38, no. 1, pp. 35-44, 1999.

[58] A. J. Edwards, B. T. Vinyard, E. R. Wiley et al., "Consumption of watermelon juice increases plasma concentrations of lycopene and $\beta$-carotene in humans," Journal of Nutrition, vol. 133, no. 4 , pp. 1043-1050, 2003.

[59] M. Richelle, K. Bortlik, S. Liardet et al., "A food-based formulation provides lycopene with the same bioavailability to humans as that from tomato paste," Journal of Nutrition, vol. 132, no. 3, pp. 404-408, 2002.

[60] O. Aust, W. Stahl, H. Sies, H. Tronnier, and U. Heinrich, "Supplementation with tomato-based products increases lycopene, phytofluene, and phytoene levels in human serum and protects against UV-light-induced erythema," International Journal for Vitamin and Nutrition Research, vol. 75, no. 1, pp. 54-60, 2005.

[61] EFSA, "Scientific Opinion on the re-evaluation of mixed carotenes (E 160a (i)) and beta-carotene (E 160a (ii)) as a food additive," EFSA Journal, vol. 10, pp. 2593-2660, 2012.

[62] EFSA, "Scientific Opinion on the re-evaluation of lutein (E 161b) as a food additive," EFSA Journal, vol. 8, pp. 1678-1735, 2010.

[63] FDA, “GRAS Notice 140," 2004, https, https://www.accessdata .fda.gov/scripts/fdcc/index.cfm?set=GRASNoticesid=140.
[64] FDA, “GRAS Notice 385,” 2011, https://www.accessdata.fda.gov/ scripts/fdcc/index.cfm? set=GRASNotices\&id=385.

[65] FDA, “GRAS Notice 390," 2012, https://www.accessdata.fda.gov/ scripts/fdcc/index.cfm? set=GRASNotices\&id=390.

[66] FDA, “GRAS Notice 432,” 2012, https://www.accessdata.fda.gov/ scripts/fdcc/index.cfm?set=GRASNotices\&id=432.

[67] FDA, “GRAS Notice 542,” 2015, https://www.accessdata.fda.gov/ scripts/fdcc/index.cfm? set=GRASNotices\&id=542.

[68] FDA, “GRAS Notice 543," 2015, https://www.accessdata.fda.gov/ scripts/fdcc/index.cfm?set=GRASNotices\&id $=543$.

[69] EFSA, "Use of lycopene as a food colour," EFSA Journal, pp. 166, 2008.

[70] EFSA, "Safety of Lycopene oleoresin from tomatoes," EFSA Journal, pp. 1-22, 2008.

[71] FDA, “GRAS Notice 119,” 2003. https://www.accessdata.fda.gov/ scripts/fdcc/index.cfm?set=GRASNotices\&amp;id=119.

[72] FDA, “GRAS Notice 163,” 2005. https://www.accessdata.fda.gov/ scripts/fdcc/index.cfm?set=GRASNotices\&amp;id=163.

[73] FDA, "GRAS Notice 185," 2006. https://www.accessdata.fda.gov/ scripts/fdcc/index.cfm?set=GRASNotices\&amp;id=185.

[74] FDA, “GRAS Notice 299," 2009. https://www.accessdata.fda.gov/ scripts/fdcc/index.cfm?set=GRASNotices\&amp;id=299.

[75] Financial Supervisory Authority, "Opinion of the safety of synthetic Zeaxanthin as an ingredient in food supplements," EFSA Journal, pp. 1-28, 2008.

[76] Financial Supervisory Authority, "Statement on the safety of synthetic zeaxanthin as an ingredient in food," EFSA Journal, vol. 2012, pp. 2891-2905, 10.

[77] FDA, “GRAS Notice 588," 2016. https://www.accessdata.fda.gov/ scripts/fdcc/index.cfm?set=GRASNotices\&amp;id=588.

[78] FDA, “GRAS Notice 639,” 2016. https://www.accessdata.fda.gov/ scripts/fdcc/index.cfm?set=GRASNotices\&amp;id=639.

[79] G. Britton and F. Khachik, "Carotenoids in Food," in Carotenoids Volume 5: Nutrition and Health, G. Britton, S. Liaaen-Jensen, H. Pfander, and G. Food, Eds., pp. 45-66, Birkhäuser, Berlin, Germany, 2009. 

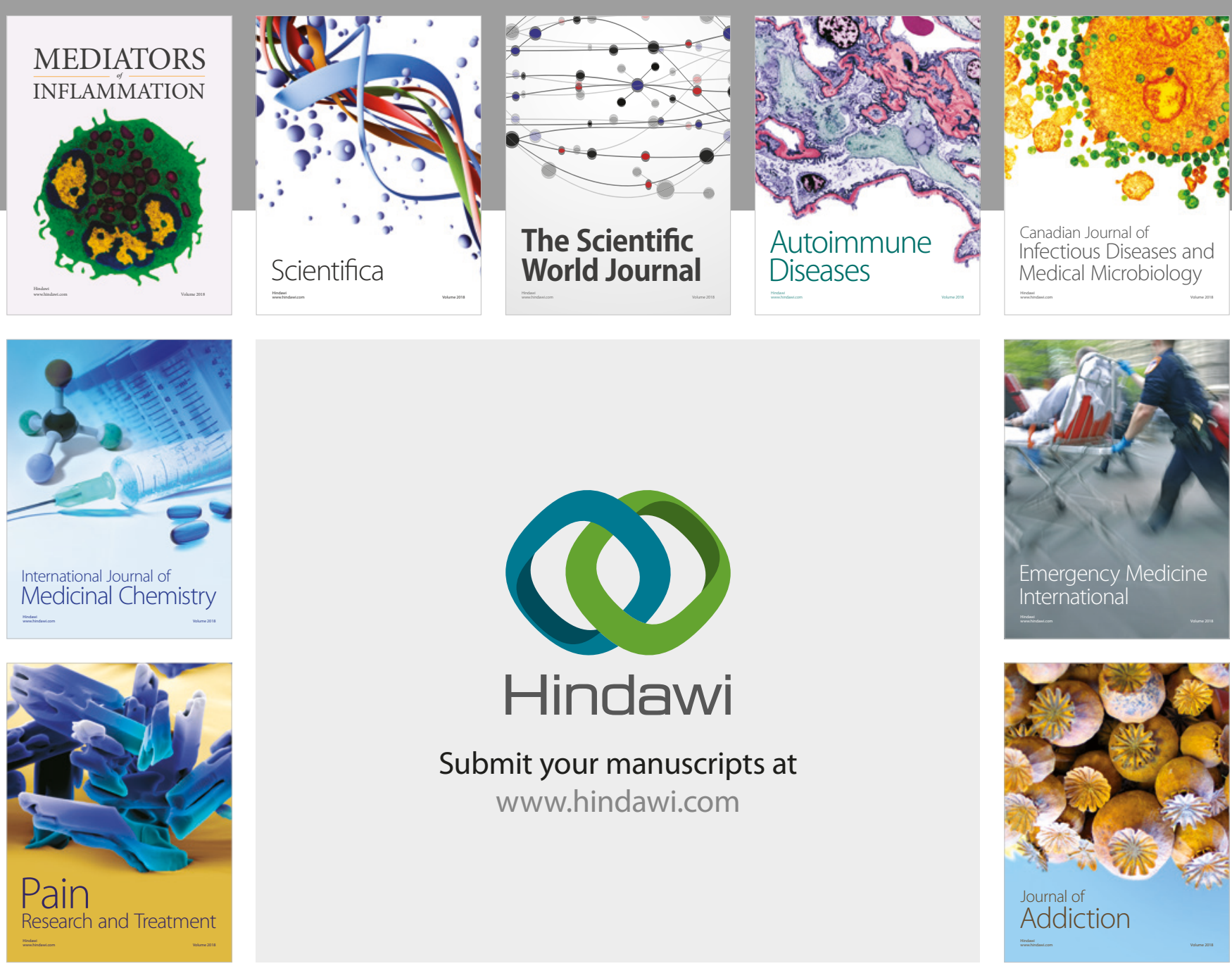

Canadian Journal of
Infectious Diseases and Medical Microbiology

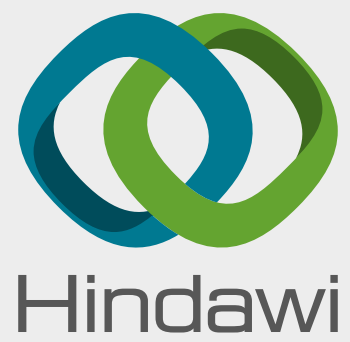

Submit your manuscripts at

www.hindawi.com
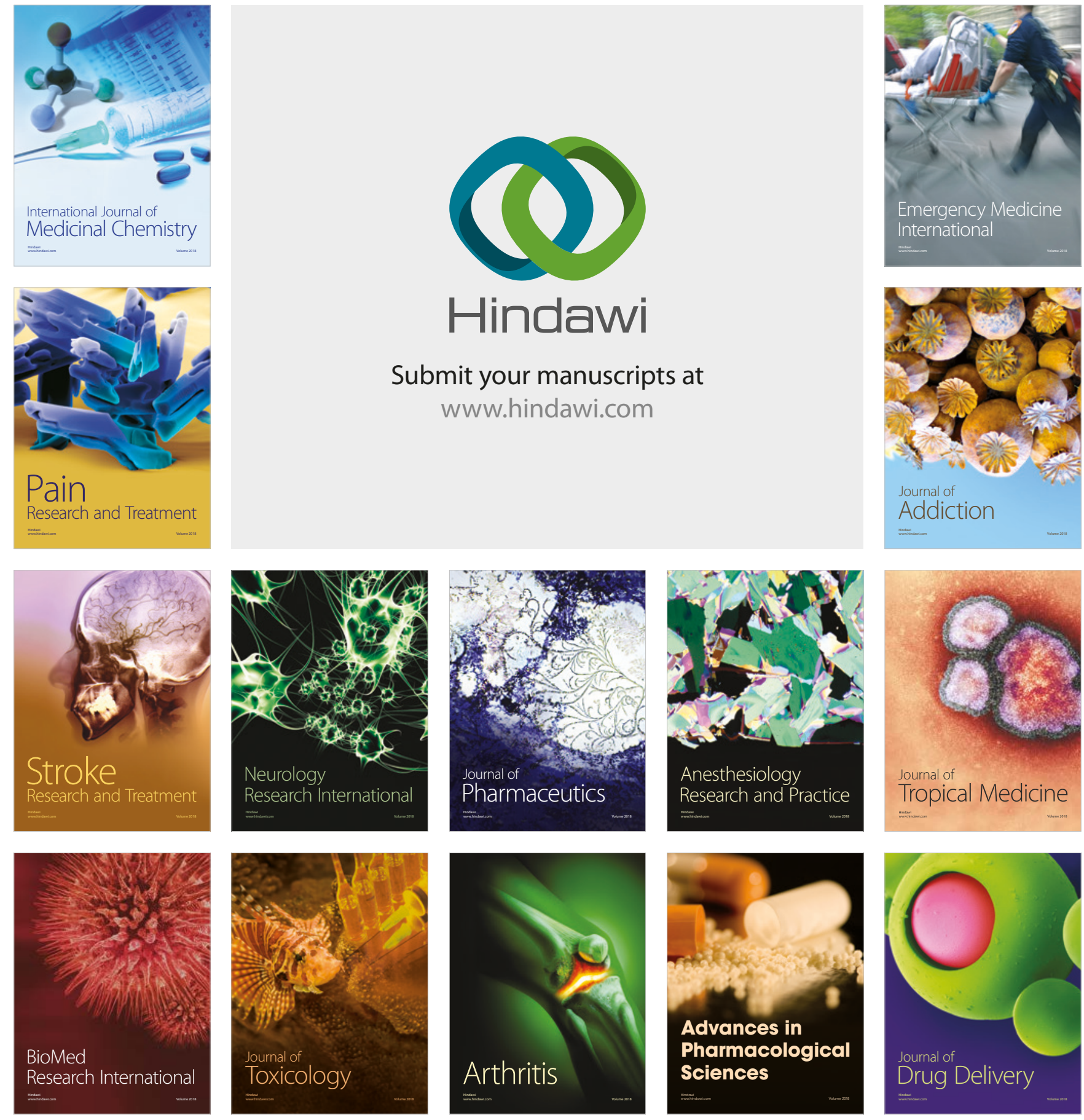